\title{
Erratum to: Exact goodness-of-fit tests for shape-scale families and type II censoring
}

\author{
Vilijandas B. Bagdonavičius • Rūta J. Levuliene • \\ Mikhail S. Nikulin
}

Published online: 6 June 2013

(C) Springer Science+Business Media New York 2013

\section{Erratum to: Lifetime Data Anal DOI 10.1007/s10985-013-9252-x}

An error occurred in the name of the first author in the original publication of the article. The correct version of the authors names is given below:

Vilijandas B. Bagdonavičius · Rūta J. Levuliene · Mikhail S. Nikulin

The online version of the original article can be found under doi:10.1007/s10985-013-9252-x.

V. B. Bagdonavičius $(\varangle) \cdot$ R. J. Levuliene

Department of Mathematical Statistics, University of Vilnius, Vilnius, Lithuania e-mail: vilijandas.bagdonavicius@mif.vu.lt

M. S. Nikulin

UFR Sciences and Modelization, University of Bordeaux-2, Bordeaux, France 